\title{
Improving rural and remote practitioners' knowledge of the diabetic foot: findings from an educational intervention
}

\author{
Deborah E. Schoen ${ }^{1 *}$, Kaniz Gausia ${ }^{1}$, David G. Glance ${ }^{2}$ and Sandra C. Thompson ${ }^{1}$
}

\begin{abstract}
Background: This study aimed to determine knowledge of national guidelines for diabetic foot assessment and risk stratification by rural and remote healthcare professionals in Western Australia and their implementation in practice. Assessment of diabetic foot knowledge, availability of equipment and delivery of foot care education in a primary healthcare setting at baseline enabled evaluation of the effectiveness of a diabetic foot education and training program for generalist healthcare professionals.

Methods: This study employed a quasi-experimental pre-test/post-test study design. Healthcare practitioners' knowledge, attitudes and practice of diabetic foot assessment, diabetic foot risks, risk stratification, and use of the 2011 National Health and Medical Research Council Guidelines were investigated with an electronic pre-test survey Healthcare professionals then undertook a 3-h education and training workshop before completing the electronic post-test knowledge, attitudes and practice survey. Comparison of pre-test/post-test survey findings was used to assess the change in knowledge, attitudes and intended practice due to the workshops.
\end{abstract}

Results: Two hundred and forty-six healthcare professionals from two rural and remote health regions of Western Australia participated in training workshops. Monofilaments and diabetes foot care education brochures, particularly brochures for Aboriginal people, were reported as not readily available in rural and remote health services. For most participants (58\%), their post-test knowledge score increased significantly from the pre-test score. Use of the Guidelines in clinical settings was low (19\%). The healthcare professionals' baseline diabetic foot knowledge was adequate to correctly identify the high risk category. However, stratification of the intermediate risk category was poor, even after training.

Conclusion: This study reports the first assessment of Western Australia's rural and remote health professionals' knowledge, attitudes and practices regarding the diabetic foot. It shows that without training, generalists' levels of knowledge concerning the diabetic foot was low and they were unlikely to assess foot risk. The findings from this study in a rural and remote setting cast doubt on the ability of generalist healthcare professionals to stratify risk appropriately, especially for those at intermediate risk, without clinical decision support tools.

Keywords: Diabetic foot, Risk stratification, Knowledge, Attitude, Practice

\footnotetext{
* Correspondence: deborah.schoen@uwa.edu.au

${ }^{1}$ Western Australian Centre for Rural Health, Faculty of Medicine, Dentistry \& Health Sciences, The University of Western Australia, 35 Stirling Highway,

Crawley, WA 6009, Australia

Full list of author information is available at the end of the article
} 


\section{Background}

Diabetic foot complications are minimised with good glycaemic control $[1,2]$ and by prevention, early identification, and management of foot risk factors [3]. Accurate diabetic foot risk stratification predicts foot ulceration $[4,5]$ and so is a crucial step in the prevention of complications. The 2011 National Health and Medical Research Council (NHMRC) National Evidence- Based Guideline on Prevention, Identification and Management of Foot Complications in Diabetes (Guideline) provided an expert consensus opinion that "[in Australia] any suitably trained health professional may perform the [foot] risk assessment [stratification]" [3]. Unfortunately, in Australia, there is limited evidence available regarding rural and remote healthcare professionals' diabetic foot knowledge and practice, or on approaches to upskilling health generalists in rural practice about the diabetic foot.

Rural and remote communities in Australia are of particular concern for diabetic foot complications. Rates of diabetes consultations are higher in rural areas than in other areas of Australia [6], rural and remote general practitioners are less confident than their urban collegues managing complications of diabetes [7] and a high proportion of diabetes consultations in very remote [8] Australia occur with Aboriginal patients [6]. There is also evidence that Aboriginal amputees are more likely to reside in a remote community [9]. Diabetes is the second greatest category of expenditure for disease in Aboriginal people, and diabetes complications are the second ranked contributor to potentially preventable hospitalisations in this population [10]. Nearly all, (98\%) of lower extremity amputations in Aboriginal people in Western Australia between 2000 and 2008 were associated with diabetes [11]. Furthermore, parts of Australia, such as Western Australia, have a shortage of podiatrists in rural and remote areas $[12,13]$. The Western Australian public health system covers 2.5 million square kilometres and is the largest area in the world covered by a single health authority, so access to specialist podiatry for those living remotely is very difficult, with a strong rationale for the training of generalists to identify foot problems early [14].

While a protocol for a Cochrane systematic review protocol on the education of healthcare professionals around the diabetic foot was published in 2013 [15], the review itself has not been published and no other reviews on this topic were identified. The majority of Cochrane systematic reviews on educating healthcare professionals on various topics include physicians and nurses. However, midwives, dieticians, pharmacists and psychologists have been included in some studies. The reviews have shown continuing professional development [16-18] using mixed interactive and didactic formats [16], printed educational materials [19-22], educational outreach [23], audit and feedback [24, 25] and multifaceted interventions [26] to be consistently effective effective methods of educating healthcare professionals. Randomised controlled diabetes studies that have included diabetes foot care education for healthcare professionals have used printed educational materials [27-32], audit and feedback [28] and multifaceted interventions $[27,28,30,32]$. These studies resulted in improvement in foot care processes; increased foot examination [27-32], increased appropriate referrals to podiatry [30, 32], increased patient education [30,32] and increased requests for protective footwear [32, 33]. Diabetic foot studies that have used continuing medical education and a pre-test/post-test study design reported improvement in healthcare professionals' diabetic foot knowledge [33-35]. Only one diabetic foot study using a pre/post-test study studies and continuing medical education reported improvement in foot care processes and increased requests for protective footwear [33]. Most recently, a non-randomized stepped-wedge design, including a single education session to nurses in a haemodialysis unit combined with patient education resulted in increased foot examinations [36]. Multifaceted interventions including education for healthcare professionals and healthcare systems interventions have the greatest impact on diabetic foot processes that can identify diabetic feet at risk and limit the progression of disease that can ultimately result in ulceration and lower extremity amputation.

This study aimed to determine knowledge of national guidelines for diabetic foot assessment and risk stratification amongst rural and remote healthcare professionals in Western Australia and their implementation in practice. The assessment of diabetic foot knowledge, availability of equipment and delivery of foot care education in a primary healthcare setting at baseline enabled evaluation of the effectiveness of a diabetic foot education and training program for generalist healthcare professionals. (Generalists included doctors, nurses, Aboriginal Health Workers, dieticians, diabetes educators, podiatrists, home and community care workers, students, patient care assistants, therapy assistants, Aboriginal Liaison Officers and Indigenous support officer). The training and education were part of a multifaceted High Risk Foot intervention [37] which included an electronic risk tool with clinical decision support [38], a Multidisciplinary Foot Ulcer Telehealth Clinic, Aboriginal diabetes foot care education brochures [39] and movies [40, 41]. The comprehensive intervention was planned using the World Health Organisation's Innovative Care for Chronic Conditions Framework [42].

\section{Methods}

\section{Study design}

This study employed a quasi-experimental pre-test/posttest study design. Healthcare practitioners' knowledge, attitudes and practices (KAP) of diabetic foot risks, 
assessment procedures, risk stratification, and use of the 2011 NHMRC Guidelines were investigated with an electronic pre-test survey [43]. Healthcare professionals then undertook a 3-h mixed interactive and didactic education and training workshop before completing the electronic post-test KAP survey. Comparison of pre-test/ post-test KAP survey findings was used to assess the change in knowledge, attitudes and intended practice due to the workshops.

\section{Study population}

Two hundred and forty-six rural and remote healthcare professionals from two country health regions of Western Australia participated in the diabetic foot workshops.

\section{Setting}

Study sites were 15 rural and remote towns in the Midwest and Pilbara regions of Western Australia. Fifteen workshops were delivered in hospitals, five in Aboriginal Community Controlled Health Organisations, five at a rural health centre, two at aged care centres, and one each at a rural university centre, a remote nursing post and rural general practice.

\section{Sampling}

Health service managers or staff development officers disseminated information to staff regarding the workshops by email, through discussion at in-house meetings and by posting workshop flyers on staff development boards around the hospitals and health services. The target group of participants was healthcare practitioners or people involved in the care of people with diabetes at risk of foot disease who could potentially perform a diabetic foot assessment.

\section{Data collection}

Data were collected between June 2012 and June 2013. The pre and post-test KAP survey responses were collected electronically with the TurningPoint ${ }^{\circ}$ audience response system [43]. This system integrates with Microsoft PowerPoint presentations to allow participants to enter survey responses on handheld keypads. TurningPoint ${ }^{\circ}$ collects, saves and displays the answers in the Microsoft PowerPoint presentation and into the Microsoft Excel spreadsheet simultaneously.

\section{Survey instrument}

Two surveys were identified from the literature as potential instruments [44, 45], but after review were not considered suitable/specific enough for this study as neither focused on diabetic foot risk assessment and stratification. Hence, for this study, NHMRC Guidelines summary recommendations $1,2,3,4$ and 7 and expert opinions 1 , $3,4,5$, and 6 which pertain to a primary healthcare setting were translated into question format and piloted for the pre and post-test KAPs [3]. Additional file 1: Changes to Knowledge Attitudes and Practice surveys resulting from piloting.

The pre-test KAP was a 42-item survey covering four content domains: demographics, knowledge, attitudes and practice. Multiple choice and yes/no closed questions were asked for 7 demographic, 16 knowledge and 16 practice questions, and for the 3 attitude questions a five-point Likert scale $(1=$ strongly agree, $5=$ strongly disagree) was used. Additional file 2: Knowledge, Attitude and Practice Survey Pre-test.

The post-test KAP survey consisted of 25 questions: 11 matched knowledge and two matched attitude questions (repeated from the pre-test); two intended practice questions; five unmatched foot deformity questions; and five evaluation questions. Additional file 3: Knowledge, Attitude and Practice Survey Post-test

\section{The education and training workshops}

All workshops commenced with a formal 'Acknowledgment of Country' to recognise the specific local Aboriginal 'tribal' group as the First Australians and custodians of the land where the workshop was taking place [46]. Workshops were face-to-face, 2 to $3 \mathrm{~h}$ in duration, limited to a maximum of 20 participants, and presented by a podiatrist.

The workshop sequence was: pre-test KAP survey; education delivery; hands on training; time for participants to practise a diabetic foot risk assessment using a risk calculator tool with clinical decision support [38]; and at the end of the session, post-test KAP survey. The education component focused on imparting knowledge, raising awareness, and promoting understanding of the diabetic foot. The training included the development of evidencebased foot assessment skills and eHealth communication skills. The workshop was interactive, informal and practical, and based on the adult learning principles that adults learn best informally and by active participation, and that Aboriginal people absorb knowledge better through experiential, hands-on learning [47-49]. The educational resources and training materials supplied to participants and the rationale for providing them are shown in Table 1 .

\section{Statistical analysis}

Pre and post-test KAP Microsoft Excel data sheets were imported to IBM SPSS Version 22 [50]. The unique identification code of each keypad allowed each participant's pre and post-test variables to be reliably matched. Negatively worded items in the surveys were reversed. Knowledge answers were recoded to correct or incorrect. Each correct answer was given a score of one point, and incorrect responses scored zero. "Don't know" responses were considered wrong and scored zero. Total pre and post-test knowledge scores were calculated as the sum of correct responses. A paired $t$-test was used to test the difference between the means of the pre and 
Table 1 Education and training materials supplied to participants

\begin{tabular}{l} 
Materials \\
\hline Printed educational materials \\
NHMRC Guidelines [3] \\
Western Australian High Risk Foot Model of Care [12] \\
The Foot Book: A manual for Aboriginal Health Workers about common \\
foot problems, how to recognize them and what to do about them [74] \\
Royal Perth Hospital Multidisciplinary Foot Ulcer Telehealth Clinic \\
brochure \\
Royal Perth Hospital Multidisciplinary Foot Ulcer Telehealth Clinic \\
referral form \\
Electronic educational materials on USB \\
NHMRC Guidelines [3] \\
Western Australian High Risk Foot Model of Care [12]
\end{tabular}

Diabetic foot diagnostic imaging pathways [78, 79]

Journal articles on the diabetic foot

Images of diabetic foot problems

Royal Perth Hospital Multidisciplinary Foot Ulcer Telehealth Clinic referral form

URL links useful for continuing education [80-82]

For patient assessment

10-g monofilament

Two different diabetes foot care brochures produced by Diabetes WA [39]

Resources for Aboriginal people from Diabetes WA [39]

Education brochures for patients specific to stratified level of foot risk (low, intermediate, high or ulcer care)

\section{Rationale}

Education [16, 70]

Small beneficial effect on HCP practice [19-22, 71]

Distribution/passive dissemination of PEM [19-22]

Benefit to patient outcome $[34,72,73]$

Culturally appropriate/real photographs of Aboriginal foot complications and foot deformities [75]

Communication/marketing new clinic and educate what should be referred [70]

Promote continuity and coordination of care of diabetic foot [42]

Distribution/passive dissemination of PEM [19-22]

Electronic materials equivalent effect on HCP practice to PEM [76]

EHI and education -HCP used resource more frequently [77]

Create foot folder on work computer

Ability to share information with others

Resource for students and new staff

Evidence-based pathways in HDWA

Distribution/passive dissemination of PEM [19-22]

Facilitate recognition of foot deformities $[59,62]$

Promote continuity and coordination of care of diabetic foot [42] Communication/marketing of new clinic [70]

Access to further CME if interested

Access to CME for rural and remote HCP

Online Aboriginal Cultural Orientation Training

Training [70]

Equip teams [42] Enablement [70]

Enable foot risk stratification

Enable diabetic foot education [3]

Mobilise resources [42]

Support self-management [42]

Enable culturally appropriate education

Comply with HDWA guidelines $[12,13,83,84]$

Access to education/Education targeted to foot risk

HCP Healthcare Professional, PEM Printed Education Materials, USB Universal Serial Bus, EHI Electronic Health Information, HDWA Department of Health Western Australia, CME Continuing Medical Education, PEMs, defined as the distribution of published or printed recommendations for clinical care including clinical practice guidelines, monographs, and publications in peer-reviewed journals, delivered personally or through mass mailing [85]

post-test knowledge scores, as a continuous variable, for all participants with complete pre and post-test knowledge scores. McNemar's test was used to test the difference between paired proportions for 11-matched knowledge answers and two matched attitude answers. Knowledge answers were only included in McNemar's test if all 11 knowledge questions were answered. A $p$-value of $<0.05$ was considered statistically significant, and two-tailed tests were used for significance testing.

Ethics approvals for this study were granted by The University of Western Australia Human Research Ethics
Committee (RA/4/1/5054), the Western Australian Aboriginal Health Ethics Committee (363-09/11) and the Western Australian Country Health Service Research Ethics Committee (2011:25).

\section{Results}

Participant demographics

A total of 246 healthcare professionals from two rural and remote health regions of Western Australia participated in the diabetic foot workshops. Participants were aged between 18 and 65 years; $83 \%$ were female, $14 \%$ 
identified as Aboriginal and Torres Strait Islander, and half were nurses $(51 \%)$. Table 2 displays the demographic information of the workshop participants for the total group attending education $(n=246)$ and those for whom matched pre-test and post-test knowledge scores were available $(n=117)$.

\section{Attitudes}

More than $95 \%$ of participants in both pre and post-test believed a foot ulcer is serious, and $83 \%$ believed diabetic foot problems were an issue in their community. Before training, $31 \%$ believed that only a podiatrist can stratify foot risk, and this changed significantly to $19 \%$ $(p<0.001)$ post-training.

\section{Practice}

The availability of resources to complete a diabetic foot assessment is shown in Table 3 Participants' self-reported foot assessment practice prior to training $(n=246)$. Confidence in doing an assessment increased from $34 \%$ pre-training to $95 \%$ immediately after the intervention $(p<0.001)$. Lack of time was the most frequently reported reason for not checking feet.

\section{Knowledge}

\section{Missing values and excluded scores}

Knowledge scores from over half (52.4\%) of workshop participants were excluded from paired data analysis due to missing pre-test or post-test surveys or missing responses to individual items (Fig. 1). There were several reasons for this. A total of 39 participants missed either the entire pre-test (14) or the entire post-test (25), most often due, respectively, to being late to the workshop or needing to return to work before or during the post-test. Knowledge scores for participants $(n=20)$ from five towns (two very remote, one remote and two outer regional) [8] were excluded due to an error using TurningPoint $^{\circ}$ [43]. Of the remaining 187 participants, 70 randomly missed different questions without any apparent pattern or specific questions missed. Participants who did not respond to questions had similar demographic characteristics to those who answered, except that two-thirds of the knowledge answers of Aboriginal and Torres Strait Islander participants were excluded because paired responses were not available.

\section{Changes in knowledge scores among participants providing complete pre-test/post-test data}

For most participants with paired data, their post-test knowledge score increased from the pre-test score (68/ 117; $58 \%)$. No change in knowledge score occurred for $18 \%(21 / 117)$, and $25 \%(28 / 117)$ had a pre-test score greater than post-test score (Fig. 2). There was no pattern of difference being discernible by any professional group, other than that for Home and Community Care Workers $(n=11)$ where all participants had higher posttest knowledge scores.

The mean knowledge score for the 117 participants was $6.9 \pm 1.6$ in the pre-test and $7.8 \pm 1.4$ in the posttest, a significant change in mean knowledge score $(0.9$, $95 \%$ CI $0.5-1.3)(p<0.001)$ on a two-tailed paired $t$-test.

\section{Individual knowledge questions -paired pre-test /post-test results}

Table 4 shows the change in knowledge after training based on individual paired pre-test /post-test results $(n=117)$. The difference between the 117 paired proportions of responses in pre- and post-test showed a significant difference for five of the 11 knowledge questions. Two of the three questions assessing healthcare professionals' ability to determine people at intermediate risk of diabetic foot complications improved (foot deformity and neuropathy), however, even after the training less than half of the participants could stratify intermediate foot risk correctly. For the question requiring respondents to classify people with non-palpable pulses as being at intermediate risk, there was no improvement with only $32 \%$ answering correctly in the post-test.

\section{Five unmatched foot deformity questions}

Table 5 shows the results of knowledge questions of all participants pre- and post-test (unpaired). Knowledge of the foot deformities was low in the pre-test and showed the greatest improvement in the intermediate risk category. Improvements in recognition of small muscle wasting increased from $34 \%$ of participants in the pretest to $85 \%$ in the post-test and knowing how to test for limited joint motion increased from $19 \%$ in the pre-test to $70 \%$ of participants in the post-test. More modest, but still substantial, improvements occurred in participants recognising a hammertoe (from 42 to $60 \%$ ) and claw toes (from 52 to $82 \%$ ) in pre and post-test assessment.

\section{Evaluation questions}

The workshops were well received based on the post-test evaluation, with most respondents finding the workshop content understandable (85\%), providing useful information (85\%), having appropriate quality and content of information $(87 \%)$ and stating they would recommend the workshop to colleagues (87\%).

\section{Discussion}

This study found the preexisiting use of the 2011 NHMRC guidelines was very low, stratification of the intermediate risk category was poor, even after training and the resources to complete a diabetic foot assessment are not readily available in in rural and remote Western 
Table 2 Demographic characteristics of workshop participants, including the subgroup with matched pre-test and post-test knowledge scores

\begin{tabular}{llll}
\hline Demographic & All \\
$n=246$ & (Percent) & $\begin{array}{l}\text { Matched } \\
n=117\end{array}$ & (Percent) \\
& &
\end{tabular}

\begin{tabular}{lllll}
\hline Sex & & & & \\
Male & 25 & $(10)$ & 10 & (8) \\
Female & 204 & $(83)$ & 106 & (91) \\
Missing & 17 & $(7)$ & 1 & (1)
\end{tabular}

Ethnicity

$\begin{array}{lllll}\begin{array}{l}\text { Aboriginal and } \\ \text { Torres Strait Islander }\end{array} & 32 & (14) & 11 & (9) \\ \text { Non-Aboriginal } & 193 & \text { (78) } & 104 \\ \text { Missing } & 21 & \text { (8) } & 2 & \text { (89) }\end{array}$

Age (years)

$\begin{array}{lllll}18-24 & 17 & (7) & 12 & (10) \\ 25-34 & 37 & (15) & 19 & (16) \\ 35-44 & 59 & (24) & 33 & (28) \\ 45-54 & 65 & (26) & 34 & (30) \\ 55-64 & 43 & (18) & 14 & (12) \\ 65+ & 6 & (2) & 2 & (2) \\ \text { Missing } & 19 & (8) & 3 & (3)\end{array}$

Job description

$\begin{array}{lllll}\text { Aboriginal Health Worker } & 18 & (7) & 3 & (3) \\ \text { Nurse } & 125 & (51) & 68 & (58) \\ \text { General Practitioner } & 4 & (2) & 1 & (1) \\ \text { Allied Health } & 9 & (4) & 7 & (6) \\ \text { Home and Community Care } & 11 & (4) & 6 & (5) \\ \text { Podiatrist } & 10 & (4) & 7 & (6) \\ \text { Non-clinical } & 12 & (5) & 4 & (3) \\ \text { Other } & 35 & (14) & 19 & (16) \\ \text { Missing } & 22 & (9) & 2 & (2) \\ \text { Undergraduate training } & & & & \\ \text { Metropolitan Australia } & 94 & (38) & 49 & (42) \\ \text { Rural Australia } & 94 & (38) & 51 & (44) \\ \text { Overseas } & 38 & (15) & 17 & (14) \\ \text { Missing } & 20 & (8) & 0 & (0)\end{array}$

Duration as health professional (years)

$\begin{array}{lllll}0-4 & 48 & (19) & 27 & (23) \\ 5-9 & 49 & (20) & 26 & (22) \\ 10-14 & 31 & (13) & 13 & (11) \\ 15-19 & 28 & (11) & 16 & (14) \\ 20-24 & 19 & (8) & 9 & (8) \\ 25-29 & 20 & (8) & 11 & (9) \\ 30+ & 29 & (12) & 12 & (10) \\ \text { Missing or Not applicable } & 22 & (9) & 3 & (3)\end{array}$

Table 2 Demographic characteristics of workshop participants, including the subgroup with matched pre-test and post-test knowledge scores (Continued)

\begin{tabular}{lllll}
\hline Workplace & & & & \\
$\begin{array}{l}\text { Aboriginal Community } \\
\text { Controlled Health }\end{array}$ & 40 & $(16)$ & 10 & $(9)$ \\
Organisation & & & & \\
WA Country Health Service & 102 & $(42)$ & 49 & $(42)$ \\
General Practice & 20 & $(8)$ & 18 & $(15)$ \\
$\begin{array}{l}\text { Private practitioner } \\
\text { (non-medical) }\end{array}$ & 20 & $(8)$ & 9 & $(8)$ \\
Home and Community & 6 & $(2)$ & 4 & $(3)$ \\
Care & & & & \\
Other & 41 & $(17)$ & 25 & (21) \\
Missing & 17 & $(7)$ & 2 & (2) \\
Total & 246 & & 117 &
\end{tabular}

${ }^{2}$ Other group includes: students (18), patient care assistants (9), student supervisors/lecturers (3), therapy assistants (2), Aboriginal Liaison Officers (2), Indigenous support officer (1)

Australian health services. Evaluation of the workshops was positive and improved healthcare professionals' short-term diabetic foot knowledge and confidence to complete a diabetic foot risk stratification.

The pre/post-test design used in this study enabled evaluation of the diabetic foot workshops and allowed self-evaluation by the participants, the optimal method for adult learners to self-assess their progress or success $[48,49,51]$. This approach was appropriate to apply evidence shown to be consistently effective in reducing the gap between research evidence and practice in the education of healthcare professionals [16-18, 20-22, 26, $28,52-56]$ and determine the impact of the workshops. Strengths of the study were the use of questions derived

Table 3 Participants' reported pre-training practices and foot assessment resources $(n=246)$

\begin{tabular}{ll}
\hline Statements & Percent \\
\hline Practices & 59 \\
Regularly check the feet of people with diabetes $(n=230)$ & 71 \\
$\begin{array}{l}\text { Regularly document when feet of people with diabetes } \\
\text { are checked ( } n=224)\end{array}$ & 41 \\
$\begin{array}{l}\text { Regularly provide foot care education to people with } \\
\text { diabetes ( } n=223 \text { ) }\end{array}$ & 19 \\
$\begin{array}{l}\text { Use the 2011 NHMRC risk stratifications [3] }(n=214) \\
\text { Previously trained in foot assessment }(n=218)\end{array}$ & 39 \\
Resources available in clinic & \\
Diabetes foot care brochures ( $n=227)$ & 54 \\
Aboriginal diabetes foot care brochures $(n=223)$ & 22 \\
10-g monofilament $(n=216)$ & 47 \\
\hline
\end{tabular}




\section{6 total participants}

$\longrightarrow 75$ excluded incomplete knowledge pre-test

$\downarrow$

171 complete pre-tests knowledge scores

54 excluded incomplete knowledge post-test

117 complete pre and post-test knowledge scores

Fig. 1 Knowledge scores included in paired pre-test/post-test analysis

from the 2011 NHMRC Guidelines using this as a standard based on expert consensus [3] and the inclusion of a broad range of primary healthcare professionals in the workshops reflects the reality of rural and remote practice in Western Australia. The limitation of the pre/post test design is that it reports only on intended practice; the effect on actual practice and foot care processes is unknown. Other limitations of this study were the reduced number of matched pre and post-test scores, particularly for the Aboriginal participants and no longer-term follow-up to determine if knowledge was retained.
Other Australian studies reporting higher use of the diabetic foot guidelines sampled podiatrists only, rather than the multidisciplinary sample in this study $[57,58]$. Improvement in healthcare practitioners' diabetic foot knowledge in multidisciplinary samples has been shown in other studies using a pre/post-test design and continuing medical education [33-35]. Most recently a single education session for nurses in a haemodialysis unit resulted in an increased number of foot examinations [36]. The inability of health professionals to correctly stratify diabetic foot risk, even after training, has been reported previously in an urban setting in Western

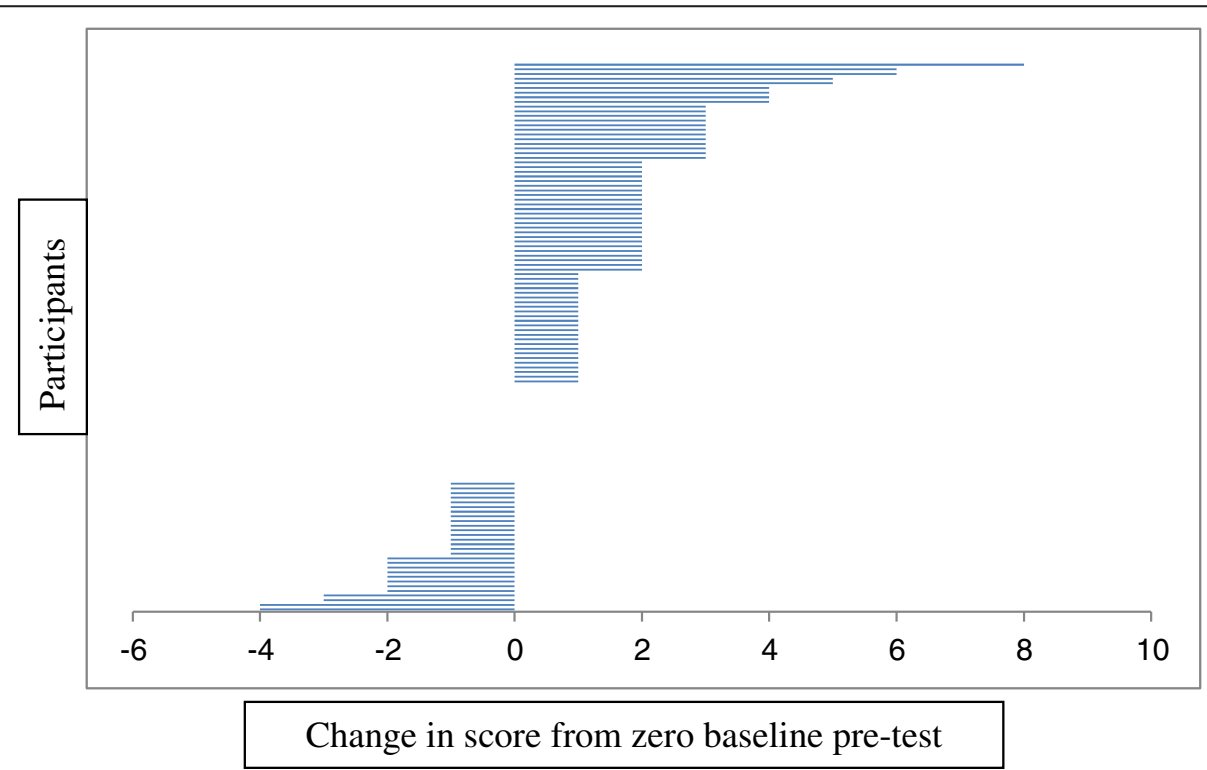

Fig. 2 Size and direction of change in knowledge score for each participant 
Table 4 Change in individual knowledge questions -paired pre-test /post-test results $(n=117)$

\begin{tabular}{|c|c|c|c|c|c|}
\hline \multirow[t]{2}{*}{ Knowledge questions } & \multicolumn{2}{|l|}{ Pre-test } & \multicolumn{2}{|l|}{ Post-test } & \multirow[b]{2}{*}{$p$-value } \\
\hline & Correct $n(\%)$ & $95 \% \mathrm{Cl}$ & Correct $n(\%)$ & $95 \% \mathrm{Cl}$ & \\
\hline People with an amputation are high risk ${ }^{a}$ & $95(81.2)$ & $74-88$ & $110(94.0)$ & $90-98$. & $0.003^{*}$ \\
\hline People with a previous foot ulcer are high risk ${ }^{a}$ & $102(87.5)$ & $81-93$ & $105(89.7)$ & $84-95$ & 0.664 \\
\hline $\begin{array}{l}\text { People with non-palpable pulses (and no other risk factors or previous history) } \\
\text { are intermediate risk }^{\text {a }}\end{array}$ & $27(23.1)$ & $15-31$ & $38(32.5)$ & $24-41$ & 0.090 \\
\hline $\begin{array}{l}\text { People unable to feel monofilament (and no other risk factors or previous history) } \\
\text { are intermediate risk }\end{array}$ & $22(18.8)$ & $12-26$ & $54(46.2)$ & $37-55$ & $<0.001^{*}$ \\
\hline $\begin{array}{l}\text { People with a foot deformity (and no other risk factors or previous history) are } \\
\text { intermediate risk }{ }^{a}\end{array}$ & $25(21.4)$ & $14-29$ & $72(61.5)$ & $53-70$ & $<0.001^{*}$ \\
\hline $\begin{array}{l}\text { People with two foot risks are high risk (and no previous history of amputation } \\
\text { or ulceration) }\end{array}$ & $103(88.0)$ & $82-94$ & $103(88.0)$ & $82-94$ & 1.000 \\
\hline Check low risk feet every 12 months $^{\mathrm{a}}$ & $52(44.4)$ & $35-53$ & $98(83.8)$ & $77-90$ & $<0.001^{*}$ \\
\hline Check high risk feet every 3 months ${ }^{a}$ & 89 (84.6) & $68-84$ & 99 (90.6) & 78-91 & 0.248 \\
\hline Palpate two pulses in each foot & $67(57.3)$ & $48-66$ & $102(87.2)$ & $81-93$ & $<0.001^{*}$ \\
\hline
\end{tabular}

${ }^{a}$ NHMRC evidence-based recommendations; $\mathrm{Cl}$ confidence interval; * statistically significant a $p$-value of $<0.05$

Australia [59]. Neither an increase in foot care processes as in other studies [27-32, 36], nor assessment of patient outcomes as reported by others $[7,60,61]$ can be determined from this study.

The clinical implication of the findings that healthcare professionals cannot identify foot deformities aligns with those reported by others $[30,59,62]$. Foot deformity was excluded from the PODUS study [5] as it was not consistently defined in the included data sets, yet it appears in most diabetic foot risk stratification systems worldwide [3, 63-66]. The qualitative nature of foot deformity limits it's inclusion in research protocols

Table 5 Results of knowledge questions ${ }^{a}$

\begin{tabular}{|c|c|c|c|c|}
\hline & $n$ & Pre-test (\%) & $n$ & Post-test (\%) \\
\hline $\begin{array}{l}\text { Do you know what a hammertoe } \\
\text { looks like? }\end{array}$ & 218 & & 213 & \\
\hline Yes & 104 & 42 & 147 & 60 \\
\hline Missing & 28 & & 33 & \\
\hline $\begin{array}{l}\text { Do you know what claw toes } \\
\text { look like? }\end{array}$ & 226 & & 201 & \\
\hline Yes & 127 & 52 & 132 & 82 \\
\hline Missing & 20 & & 45 & \\
\hline $\begin{array}{l}\text { Do you know what small } \\
\text { muscle wasting looks like? }\end{array}$ & 220 & & 208 & \\
\hline Yes & 83 & 34 & 164 & 85 \\
\hline Missing & 26 & & 38 & \\
\hline $\begin{array}{l}\text { Do you know how to test for } \\
\text { limited joint motion? }\end{array}$ & 225 & & 207 & \\
\hline Yes & 46 & 19 & 172 & 70 \\
\hline Missing & 21 & & 39 & \\
\hline
\end{tabular}

${ }^{a}$ Note: Participants' responses are not paired despite it's recognised clinical importance as a risk factor for diabetic foot ulceration. This study supports the NHMRC expert consensus that health professionals in Australia need to be suitably trained to perform diabetic foot risk stratification [3]. An Australian diabetic foot education programme such as the interactive online diabetic foot training offered by the Scottish Diabetes Group and University of Edinburgh's Foot Risk Awareness and Management Education (FRAME) program is warranted to support healthcare professionals to develop and maintain the necessary skills and competencies in diabetic foot examination [67].

The question of whether or not generalists can competently complete foot risk stratification is still unresolved from this study. Alternative approaches to education and training such as the FRAME program [67] or telehealth education, now offered by Diabetes WA in Western Australia need to be evaluated [68]. Similarly, the Indigenous Diabetic Foot Program, a 2-day program particularly for Aboriginal and Torres Strait Islander peoples to encourage diabetic foot assessment, requires evaluation [69].

\section{Conclusion}

This study reports the first assessment of Western Australia's rural and remote health professionals' knowledge, attitudes and practices regarding the diabetic foot. It shows that without training, generalists' levels of knowledge concerning the diabetic foot was low and they were unlikely to assess foot risk. The findings from this study in a rural and remote setting cast doubt on the ability of generalist healthcare professionals to stratify risk appropriately, especially for those at intermediate risk, without clinical decision support tools. Alternative 
approaches to training which reliably improve knowledge and support consolidation of learning and translation into practice over the longer term need to be trialled and assessed.

\section{Additional files}

Additional file 1: Knowledge, Attitudes and Practice Survey resulting from piloting. (DOCX $24 \mathrm{~kb}$ )

Additional file 2: Knowledge, Attitude and Practice Survey Pre-test. (DOCX $30 \mathrm{~kb}$ )

Additional file 3: Knowledge, Attitude and Practice Survey Post-test. (DOCX $1821 \mathrm{~kb})$

\section{Abbreviations}

$\mathrm{Cl}$, Confidence interval; $\mathrm{CME}$, Continuing Medical Education; EHI, Electronic Health Information; FRAME, Foot Risk Awareness and Management Education; HDWA, Department of Health Western Australia; HCP, Healthcare Professional; KAP, Knowledge, attitudes and practices; NHMRC, National Health and Medical Research Council; PEM, Printed Education Materials; USB, Universal Serial Bus; WA, Western Australia

\section{Acknowledgements}

Winthrop Professor Paul Norman for reading and providing comments on original submission.

\section{Funding}

A Rural Health Continuing Education Grant from the Commonwealth Government Department of Health and Ageing funded 16 workshops. A Health Workforce Australia Simulation Grant funded an additional 12 simulation workshops. The High Risk Foot Simulation workshops were part of a larger grant to develop education in a simulated environment that was awarded to the Western Australian Centre for Rural Health [37].

\section{Availability of data and materials}

The datasets during and/or analysed during the current study available from the corresponding author on reasonable request.

\section{Authors' contributions}

DES and SCT designed the educational intervention. DES delivered the education, researched data, wrote the manuscript and reviewed/edited manuscript. DES and KG completed statistical analysis. SCT, KG and DGG contributed to the discussion and reviewed/edited manuscript. All authors read and approved the final manuscript.

\section{Competing interests}

The authors declare that they have no competing interests.

\section{Consent for publication}

Not applicable.

\section{Ethics approval and consent to participate}

Ethics approvals for this study were granted by The University of Western Australia Human Research Ethics Committee (RA/4/1/5054), the Western Australian Aboriginal Health Ethics Committee (363-09/11) and the Western Australian Country Health Service Research Ethics Committee (2011:25). All participants gave informed and written consent to take part and for dissemination of the findings in peer reviewed journals.

\section{Author details}

${ }^{1}$ Western Australian Centre for Rural Health, Faculty of Medicine, Dentistry \& Health Sciences, The University of Western Australia, 35 Stirling Highway, Crawley, WA 6009, Australia. ${ }^{2}$ Centre for Software Practice, The University of Western Australia, 35 Stirling Highway, Crawley, WA 6009, Australia.

Received: 14 March 2016 Accepted: 21 July 2016

Published online: 29 July 2016

\section{References}

1. UK Prospective Diabetes Study (UKPDS) Group. Intensive blood-glucose control with sulphonylureas or insulin compared with conventional treatment and risk of complications in patients with type 2 diabetes (UKPDS 33). Lancet. 1998;3529131:837-53.

2. Baxter M, Hudson R, Mahon J, Bartlett C, Samyshkin Y, Alexiou D, et al. Estimating the impact of better management of glycaemic control in adults with Type 1 and Type 2 diabetes on the number of clinical complications, and the associated financial benefit. Diabet Med. 2016. doi:10.1111/dme.13062.

3. National Health and Medical Research Council. National evidence-based guideline: prevention, identification and management of foot complications in diabetes. (Part of the Guidelines on the management of Type 2 Diabetes). National Health and Medical Research Council, Melbourne. 2011. http://t2dgr. bakeridi.edu.au/LinkClick.aspx?fileticket=anrL23t3ADw\%3d\&tabid=172. Accessed 10 Apr 2011

4. Leese GP, Reid F, Green V, McAlpine R, Cunningham S, Emslie-Smith AM, et al. Stratification of foot ulcer risk in patients with diabetes: a population-based study. Int J Clin Pract. 2006:605:541-5. doi:10.1111/j.1368-5031.2006.00899.x

5. Crawford F, Cezard G, Chappell FM, Murray GD, Price JF, Sheikh A, et al. A systematic review and individual patient data meta-analysis of prognostic factors for foot ulceration in people with diabetes: the international research collaboration for the prediction of diabetic foot ulcerations (PODUS). Health Technol Assess. 2015;1957:1-210. doi:10.3310/hta19570.

6. Knox S, Britt H, Pan Y, Miller GC, Bayram C, Valenti L, et al. Locality matters: the influence of geography on general practice activity in Australia 1998-2004. Canberra: Australian Institute of Health and Welfare; 2005.

7. Thepwongsa I, Kirby C, Paul C, Piterman L. Management of type 2 diabetes: Australian rural and remote general practitioners' knowledge, attitudes, and practices. Rural Remote Health. 2014:14:2499.

8. The Australian Statistical Geography Standard (ASGS) Remoteness Structure [database on the Internet]. Australian Bureau of Statistics. 2006. Available from: http://www.abs.gov.au/websitedbs/D3310114.nsf/home/remoteness +structure. Accessed 19 Jun 2011

9. O'Rourke S, Steffen C, Raulli A, Tulip F. Diabetic major amputation in Far North Queensland 1998-2008: what is the Gap for Indigenous patients? Aust J Rural Health. 2013;215:268-73. doi:10.1111/ajr.12044.

10. Australian Institute of Health and Welfare. Expenditure on health for Aboriginal and Torres Strait Islander people 2010-11: an analysis by remoteness and disease. Canberra: AlHW. 2013. http://aihw.gov.au/ WorkArea/DownloadAsset.aspx?id=60129544363. Accessed 25 Aug 2013

11. Norman PE, Schoen DE, Gurr JM, Kolybaba ML. High rates of amputation among Indigenous people in Western Australia. Med J Aust. 2010;1927:421.

12. Department of Health Western Australia. Model of care for the high risk foot. Health Networks Branch, Perth. 2010. http://www.healthnetworks. health.wa.gov.au/modelsofcare/docs/High_Risk_Foot_Model_of_Care.pdf. Accessed 17 Jun 2010

13. Department of Health Western Australia. Diabetes in Western Australia: prevalence and services in 2012. Health Networks Branch, Perth. 2012 http://www.healthnetworks.health.wa.gov.au/docs/WA_diabetes_services_ review Report.pdf. Accessed 16 Apr 2013

14. Department of Health Western Australia. WA Country Health Service. Northam. http://ww2.health.wa.gov.au/Careers/International-applicants/International-medicalgraduates-IMGs/Overview-of-the-WA-health-system. Accessed 16 Apr 2012

15. Francis DK, Lazzarini PA, Ferguson TS, Jen SD, Cumberbatch C, Welch V, et al. Education of health professionals for preventing diabetic foot ulceration. Cochrane Database Syst Rev. 2013;3, CD010433. doi:10.1002/ 14651858.cd010433.

16. Forsetlund L, Bjorndal A, Rashidian A, Jamtvedt G, O'Brien MA, Wolf F, et al. Continuing education meetings and workshops: effects on professional practice and health care outcomes. Cochrane Database Syst Rev. 2009;2 CD003030. doi:10.1002/14651858.CD003030.pub2.

17. Bloom BS. Effects of continuing medical education on improving physician clinical care and patient health: a review of systematic reviews. Int J Technol Assess Health Care. 2005;213:380-5

18. Umble KE, Cervero RM. Impact studies in continuing education for health professionals. A critique of the research syntheses. Eval Health Prof. 1996;192:148-74.

19. Farmer AP, Legare F, Turcot L, Grimshaw J, Harvey E, McGowan JL, et al. Printed educational materials: effects on professional practice and health care outcomes. Cochrane Database Syst Rev. 2008;3, CD004398. doi:10.1002/ 14651858.CD004398.pub2. 
20. Giguere A, Legare F, Grimshaw J, Turcotte S, Fiander M, Grudniewicz A, et al. Printed educational materials: effects on professional practice and healthcare outcomes. Cochrane Database Syst Rev. 2012;1010, CD004398. doi:10.1002/14651858.CD004398.pub3.

21. Grimshaw JM, Thomas RE, MacLennan G, Fraser C, Ramsay CR, Vale L, et al. Effectiveness and efficiency of guideline dissemination and implementation strategies. Health Technol Assess. 2004;86:iii-iv. 1-72.

22. Hakkennes S, Dodd K. Guideline implementation in allied health professions: a systematic review of the literature. Qual Saf Health Care. 2008;174:296-300. doi:10.1136/qshc.2007.023804.

23. O'Brien MA, Rogers S, Jamtvedt G, Oxman AD, Odgaard-Jensen J, Kristoffersen DT, et al. Educational outreach visits: effects on professional practice and health care outcomes. Cochrane Database Syst Rev. 2007:4, CD000409. doi:10.1002/14651858.CD000409.pub2.

24. Ivers N, Jamtvedt G, Flottorp S, Young JM, Odgaard-Jensen J, French SD, et al. Audit and feedback: effects on professional practice and healthcare outcomes. Cochrane Database Syst Rev. 2012;66, CD000259. doi:10.1002/ 14651858.CD000259.pub3.

25. Ivers NM, Grimshaw JM, Jamtvedt G, Flottorp S, O'Brien MA, French SD, et al. Growing literature, stagnant science? Systematic review, meta-regression and cumulative analysis of audit and feedback interventions in health care. J Gen Intern Med. 2014;2911:1534-41. doi:10.1007/s11606-014-2913-y.

26. Renders CM, Valk GD, Griffin S, Wagner EH, Eijk JT, Assendelft WJ. Interventions to improve the management of diabetes mellitus in primary care, outpatient and community settings. Cochrane Database Syst Rev. 2001;1, CD001481. doi:10.1002/14651858.CD001481

27. McDermott RA, Schmidt BA, Sinha A, Mills P. Improving diabetes care in the primary healthcare setting: a randomised cluster trial in remote Indigenous communities. Med J Aust. 2001;17410:497-502.

28. Frijling BD, Lobo CM, Hulscher ME, Akkermans RP, Braspenning JC, Prins A, et al. Multifaceted support to improve clinical decision making in diabetes care: a randomized controlled trial in general practice. Diabet Med. 2002; 1910:836-42.

29. Glasgow RE, Nutting PA, King DK, Nelson CC, Cutter G, Gaglio B, et al. A practical randomized trial to improve diabetes care. J Gen Intern Med. 2004;1912:1167-74. doi:10.1111/j.1525-1497.2004.30425.x

30. Litzelman DK, Slemenda CW, Langefeld CD, Hays LM, Welch MA, Bild DE, et al. Reduction of lower extremity clinical abnormalities in patients with non-insulin-dependent diabetes mellitus. A randomized, controlled trial. Ann Intern Med. 1993;1191:36-41.

31. Meigs JB, Cagliero E, Dubey A, Murphy-Sheehy P, Gildesgame C, Chueh H, et al. A controlled trial of web-based diabetes disease management: the MGH diabetes primary care improvement project. Diabetes Care. 2003;263:750-7.

32. Donohoe ME, Fletton JA, Hook A, Powell R, Robinson I, Stead JW, et al. Improving foot care for people with diabetes mellitus-a randomized controlled trial of an integrated care approach. Diabet Med. 2000;178:581-7.

33. Pataky Z, Golay A, Rieker A, Grandjean R, Schiesari L, Vuagnat H. A first evaluation of an educational program for health care providers in a longterm care facility to prevent foot complications. Int J Low Extrem Wounds. 2007:62:69-75. doi:10.1177/1534734607302238.

34. Jones J, Gorman A. Evaluation of the impact of an educational initiative in diabetic foot management. Br J Community Nurs. 2004;93:S20-6. doi:10. 12968/bjcn.2004.9.Sup1.12504.

35. Parker MT, Leggett-Frazier N, Vincent PA, Swanson MS. The impact of an educational program on improving diabetes knowledge and changing behaviors of nurses in long-term care facilities. Diabetes Educ. 1995;216:541-5.

36. Brand SL, Musgrove A, Jeffcoate WJ, Lincoln NB. Evaluation of the effect of nurse education on patient-reported foot checks and foot care behaviour of people with diabetes receiving haemodialysis. Diabet Med. 2016;332:204-7. doi:10.1111/dme.12831.

37. Western Australian Centre for Rural Health. High risk foot project. Geraldton. 2011. http://www.cucrh.uwa.edu.au/index.php/research/phd-research/190high-risk-foot-model-of-care. Accessed 22 Feb 2011

38. Schoen DE, Glance DG, Thompson SC. Clinical decision support software for diabetic foot risk stratification: development and formative evaluation. J Foot Ankle Res. 2015:8:73. doi:10.1186/s13047-015-0128-z.

39. Diabetes WA. Got diabetes? Look after your feet. Perth: Diabetes WA; 2011 http://diabeteswa.com.au/wp-content/uploads/2016/07/got-diabetes-A3posterV3.compressed.pdf Accessed 27 Aug 2011.

40. Goolarri Media Enterprises. Bran Nue Leg. Broome 2013. https://vimeo.com/ 69131503. Accessed 25 June 2013.
41. Goolarri Media Enterprises. Deadly (And Not In A Good Way). Broome. 2014. https://vimeo.com/85494467. Accessed 31 Jan 2014

42. World Health Organisation. The innovative care for chronic conditions framework: building blocks for action. WHO, Geneva. 2002. http://www.who. int/chp/knowledge/publications/icccreport/en/. Accessed 29 July 2011

43. Turning Technologies Partners LLC. Keepad Interactive. Youngstown: Turning Technologies Partners, LLC; 2008.

44. Wu SC, Jensen JL, Weber AK, Robinson DE, Armstrong DG. Use of pressure offloading devices in diabetic foot ulcers: do we practice what we preach? Diabetes Care. 2008;3111:2118-9. doi:10.2337/dc08-0771.

45. Shiu AT, Wong RY. Diabetes foot care knowledge: a survey of registered nurses. J Clin Nurs. 2011;2015-16:2367-70. doi:10.1111/j.1365-2702.2011.03748.x.

46. National Aboriginal Community Controlled Health Organisation. 2007. http://www.naccho.org.au/aboriginal-health/definitions/. Accessed 6 May 2015

47. Knowles MS. Adult learning-processes-pedagogy and andragogy. Relig Educ 1977:722:202-11. doi:10.1080/0034408770720210.

48. Byrnes J. Aboriginal learning styles and adult education: is a synthesis possible? Australian Journal of Adult and Community Education. 1993; 333:157-71

49. Jacobson W. Learning, culture, and learning culture. Adult Educ Q. 1996;471:15-28

50. Corp IBM. IBM SPSS statistics for Windows, Version 22.0. Armonk: International Business Machines Corporation; 2012.

51. Knowles ML, Holton III EF, Swanson RA. The adult learner: the definitive classic in adult education and human resource development. 6th ed. Amsterdam: Elsevier; 2005.

52. Grimshaw JM, Shirran L, Thomas R, Mowatt G, Fraser C, Bero L, et al. Changing provider behavior: an overview of systematic reviews of interventions. Med Care. 2001:398 Suppl 2:112-1145.

53. Evans-Lacko S, Jarrett M, McCrone $P$, Thornicroft G. Facilitators and barriers to implementing clinical care pathways. BMC Health Serv Res. 2010;10:182 doi:10.1186/1472-6963-10-182.

54. Grimshaw JM, Eccles MP, Walker AE, Thomas RE. Changing physicians' behavior: what works and thoughts on getting more things to work. J Contin Educ Health Prof. 2002;224:237-43. doi:10.1002/chp.1340220408.

55. Wensing M, Bosch M, Foy R, Van der Weijden T, Eccles M, R. G, et al. Factors in theories on behaviour change to guide implementation and quality improvement in healthcare. Nijmegen: University of Nijmegen; 2005

56. Wensing $M$, Bosch $M$, Grol R. Developing and selecting interventions for translating knowledge to action. CMAJ. 2010;1822:E85-8. doi:10.1503/cmaj. 081233.

57. Bergin SM, Brand CA, Colman PG, Campbell DA. An evaluation of community-based resources for management of diabetes-related foot disorders in an Australian population. Aust Health Rev. 2009:334:671-8.

58. Quinton TR, Lazzarini PA, Boyle FM, Russell AW, Armstrong DG. How do Australian podiatrists manage patients with diabetes? The Australian diabetic foot management survey. J Foot Ankle Res. 2015;8:16. doi:10.1186/ s13047-015-0072-y.

59. Bower VM, Hobbs M. Validation of the basic foot screening checklist: a population screening tool for identifying foot ulcer risk in people with diabetes mellitus. J Am Podiatr Med Assoc. 2009;994:339-47.

60. Paul CL, Piterman L, Shaw J, Kirby C, Sanson-Fisher RW, Carey ML, et al. Diabetes in rural towns: effectiveness of continuing education and feedback for healthcare providers in altering diabetes outcomes at a population level: protocol for a cluster randomised controlled trial. Implement Sci. 2013:8:30. doi:10.1186/1748-5908-8-30.

61. Vinicor F, Cohen SJ, Mazzuca SA, Moorman N, Wheeler M, Kuebler T, et al. DIABEDS: a randomized trial of the effects of physician and/or patient education on diabetes patient outcomes. J Chronic Dis. 1987:404:345-56

62. Edelman D, Sanders LJ, Pogach L. Reproducibility and accuracy among primary care providers of a screening examination for foot ulcer risk among diabetic patients. Prev Med. 1998;272:274-8. doi:10.1006/pmed. 1998.0263.

63. Boulton AJ, Armstrong DG, Albert SF, Frykberg RG, Hellman R, Kirkman MS, et al. Comprehensive foot examination and risk assessment: a report of the task force of the foot care interest group of the American Diabetes Association, with endorsement by the American Association of Clinical Endocrinologists. Diabetes Care. 2008;318:1679-85. doi:10.2337/dc08-9021. 
64. International Working Group on the Diabetic Foot. IWGDF Guidance on the prevention of foot ulcers in at-risk patients with diabetes. International Working Group on the Diabetic Foot, Amsterdam. 2015. http://www.iwgdf. org/files/2015/website prevention.pdf. Accessed 25 Feb 2016

65. Scottish Intercollegiate Guidelines Network. Management of diabetes A national clinical guideline. Edinburgh: Scottish Intercollegiate Guidelines Network; 2010. http://www.sign.ac.uk/guidelines/fulltext/116/index.html. Accessed 5 Apr 2011.

66. National Institute for Health and Clinical Excellence. Diabetic foot problems: prevention and management (NG19). NICE, London. 2016. https://www.nice. org.uk/guidance/ng19/resources/diabetic-foot-problems-prevention-andmanagement-1837279828933. Accessed 10 Jun 2016

67. Scottish Government. The Foot Risk Awareness and Management Education (FRAME). Edinburgh: Scottish Intercollegiate Guidelines Network; 2010. http://www.diabetesframe.org/. Accessed 20 Apr 2012

68. Diabetes WA. Diabetes WA, Perth. 2011. http://www.diabeteswa.com.au/ Accessed 25 Mar 2011

69. Warnock J. Indigenous diabetic foot program. Mundingburra: Jason Warnock; 2009. http://www.diabeticfootprograms.com.au. Accessed 25 Mar 2011.

70. Michie S, van Stralen MM, West R. The behaviour change wheel: a new method for characterising and designing behaviour change interventions. Implement Sci. 2011;6:42. doi:10.1186/1748-5908-6-42.

71. Thomas L, Cullum N, McColl E, Rousseau N, Soutter J, Steen N. Guidelines in professions allied to medicine. Cochrane Database Syst Rev. 2000;2, CD000349. doi:10.1002/14651858.CD000349.

72. Piette JD, Weinberger M, McPhee SJ, Mah CA, Kraemer FB, Crapo LM. Do automated calls with nurse follow-up improve self-care and glycemic control among vulnerable patients with diabetes? Am J Med. 2000;1081:20-7.

73. Rith-Najarian S, Branchaud C, Beaulieu O, Gohdes D, Simonson G, Mazze R. Reducing lower-extremity amputations due to diabetes-application of the staged diabetes management approach in a primary care setting. J Fam Pract. 1998;472:127-32.

74. Jones S, Wilson K. The foot book: a manual for aboriginal health workers about common foot problems, how to recognise them and what to do about them. 3rd ed. Adelaide: University of South Australia and Nunkuwarrin Yunti of South Australia Inc.; 2001.

75. Schoen D, Balchin D, Thompson S. Health promotion resources for Aboriginal people: lessons learned from consultation and evaluation of diabetes foot care resources. Health Promot J Austr. 2010;211:64-9.

76. Jousimaa J, Makela M, Kunnamo L, MacLennan G, Grimshaw JM. Primary care guidelines on consultation practices: the effectiveness of computerized versus paper-based versions-a cluster randomized controlled trial among newly qualified primary care physicians. Int J Technol Assess Health Care. 2002;183:586-96.

77. Fiander M, McGowan J, Grad R, Pluye P, Hannes K, Labrecque M, et al. Interventions to increase the use of electronic health information by healthcare practitioners to improve clinical practice and patient outcomes. Cochrane Database Syst Rev. 2015;33, CD004749. doi:10.1002/14651858. CD004749.pub3.

78. Department of Health Western Australia. Diagnostic imaging pathways foot ulcer (diabetic). Department of Health Western Australia, Perth. 2009. http://imagingpathways.health.wa.gov.au/index.php/imaging-pathways/ musculoskeletal-trauma/musculoskeletal/diabetic-foot-ulcer\#pathway. Accessed 29 May 2011

79. Department of Health Western Australia. Diagnostic imaging pathwaysperipheral vascular disease. Department of Health Western Australia, Perth. 2009. http://imagingpathways.health.wa.gov.au/index.php/imaging-pathways/ cardiovascular/peripheral-vascular-disease\#pathway. Accessed 29 May 2011

80. Department of Health Queensland. Parrot (Pathways to Rural and Remote Orientation Training). Health Department of Queensland. 2010. http://health. qld.gov.au/parrot/. Accessed 29 May 2011

81. Department of Health Western Australia. WoundsWest. Department of Health Western Australia, Perth. 2008. http://www.health.wa.gov.au/ woundswest/home/. Accessed 25 Mar 2011

82. Western Australian Centre for Rural Health. Aboriginal cultural orientation training. Western Australian Centre for Rural Health, Geraldton. 2010. http://Ims.cucrh.uwa.edu.au/login/index.php. Accessed 13 Feb 2011

83. Department of Health Western Australia. WA chronic health conditions framework 2011-2016. Health Networks Branch, Perth. 2012. http://www. healthnetworks.health.wa.gov.au/docs/1112_ChronicHealthConditions Framework.pdf. Accessed 15 Jun 2011
84. Department of Health Western Australia. Foot care for people with diabetes: Western Australia standards and clinical guidelines. Health Strategy and Networks, Perth. 2014. http://www.healthnetworks.health.wa.gov.au/docs/ Foot_Care_for_People_with_Diabetes.pdf. Accessed 1 Dec 2014

85. Grol R, Grimshaw J. From best evidence to best practice: effective implementation of change in patients' care. Lancet. 2003;3629391:1225-30. doi:10.1016/S0140-6736(03)14546-1.

\section{Submit your next manuscript to BioMed Central and we will help you at every step:}

- We accept pre-submission inquiries

- Our selector tool helps you to find the most relevant journal

- We provide round the clock customer support

- Convenient online submission

- Thorough peer review

- Inclusion in PubMed and all major indexing services

- Maximum visibility for your research

Submit your manuscript at www.biomedcentral.com/submit
Biomed Central 